\title{
A model for pushover analysis of confined masonry structures: implementation and validation
}

\section{Rui Marques* and Paulo B. Lourenço}

Institute for Sustainability and Innovation in Structural Engineering, University of Minho, Campus de Azurém, 4800-058 Guimarães, PORTUGAL

*Corresponding author: marquesmnc@sapo.pt; Tel.: +351 253510 215; Fax: +351 253510217

\begin{abstract}
Confined masonry (CM) is a typical building technique in Latin American countries. This technique, due to its simplicity of construction and similarity with traditional practices of reinforced concrete building, presents a potential of use in European regions with moderate-to-high seismicity. However, most of the procedures for seismic design in codes for Latin America are force-based, which appears to be inadequate due to the high dissipative response observed for CM. This paper presents a simplified numerical-analytical approach to model CM structures using pushover analysis, aiming to apply performance-based design procedures. First, a data mining process is performed on a database of experimental results collected from lateral tests on CM walls to adjust prediction models for the wall shear strength and to determine the input relevance through a sensitivity analysis. Then, an analytical model of CM structures for pushover analysis is proposed with basis on a wide-column approach that employs an adaptive shear load-displacement constitutive relation. The proposed method is compared with a discrete element model that represents explicitly the confinements-masonry interaction, against the experimental results obtained in a quasi-static test of a full-scale tridimensional CM structure. The accuracy of the predictions from both methods is very satisfactory, allowing to capture the base sheardisplacement envelope and also the damage patterns of the structure, thus, demonstrating the ability of the methods to be used in performance-based seismic assessment and design of CM buildings.
\end{abstract}

Keywords: seismic loading, data mining, shear strength, wide-column model, discrete element model, quasi-static test 


\section{Introduction}

The use of confined masonry (CM) was, subsequently to the dissemination of reinforced concrete, one of the first actions for sustainability in housing construction in the last century, since CM was introduced in seismic-prone regions to allow earthquake resistance at a lower cost, using local materials and skills. The preservation of this construction technique, mostly in Latin American countries, and the sustainability aspects are good reasons for the development of modern analysis procedures for seismic assessment and design of CM buildings. These procedures need to account for the particularities of the construction technique and to explore the intrinsic capabilities of CM systems for performance-based methodologies. In this direction, numerical and analytical studies are addressed regarding the capacity design of CM buildings by means of pushover analysis.

Historically, CM was first introduced in Italy and Chile reacting to destructive earthquakes (1908 Messina and 1929 Talca quakes, respectively), which almost completely destroyed traditional unreinforced masonry buildings. On the contrary, according to Brzev (2007), CM buildings showed a good performance when subjected to the 1939 Chilean earthquake, and this was probably the main reason for the large dissemination of this technique in Chile, which was later on extended to all Latin America. This typology was first used in low-rise family dwellings (up to 2 storeys), and later as a low-cost solution for urban expansion, using 3-4 storey high buildings (Moroni et al. 2002). The construction with CM spread widely to all Continents, in countries with moderate-to-high seismicity such as Slovenia, India, New Zealand, Japan or Canada.

However, even if early codes were introduced for CM construction, these were mainly prescriptive (e.g., “Ordenanza General de Urbanismo y Construcción” of 1940 in Chile). Design rules for seismic capacity were not specified or applied, with insufficient seismic performance of CM buildings observed even for more recent construction, e.g. in the 2007 Pisco (San Bartolomé 2007) and 2010 Chile (Brzev et al. 2010) earthquakes. This means that, although CM started to be studied as an earthquake-resistant engineered solution in the 1960s by Meli et al. (1968 and 1974), the common practice of design and construction seem to be partly insufficient or inadequate. This is especially true when applied to building configurations that in many cases present structural particularities which can only be considered through the evaluation of the global building behavior, instead of local structural verifications. 
Conceptually, the CM system is based on embracing masonry panels with frame elements, similarly to reinforced concrete (RC) frames, but with the difference that in the CM the RC elements are cast only after the masonry construction. For this reason, contrarily to RC structures where infill masonry is built after concrete hardening, in the case of CM most of the building weight rests on the masonry panels. In addition, due to concrete shrinkage, the connection between masonry and concrete is very effective (Jäger and Schöps 2009). The interaction between the confining elements and the masonry panel allows a CM wall under lateral loading to behave as a whole up to large deformation levels, allowing improved strength and ductility, as shown e.g. in Gouveia and Lourenço (2007).

\section{Lateral cyclic response of CM walls}

Unlike a traditional masonry building, e.g. in Lourenço et al. (2011), loading induced by an earthquake on a modern masonry building can be assumed as a seismic action that mobilizes the in-plane walls parallel to the direction of the motion (Lourenço et al. 2013). This approach has been commonly assumed in the case of modern unreinforced masonry buildings and when applying nonlinear static (pushover) analysis procedures, both in terms of research, e.g. the N2 method by Fajfar and Fischinger (1988), and regulations such as the Eurocode 8 (CEN 2005) or the Italian code (NTC 2008). Pushover analyses allow exploring the inelastic capacity of buildings by deformation and energy dissipation. In the case of CM buildings the structure is composed by an assemblage of confined walls, each with different geometric and loading conditions, such that the individual response of every wall contributes to the global response of the building. Therefore, the CM wall shear load-displacement response, which can be obtained by lateral cyclic loading tests, needs to be established and, subsequently, integrated in a model for analysis of the entire CM building.

\subsection{Existing strength criteria}

The experimental response of CM walls under lateral cyclic loading has been evaluated in several countries by different authors, leading to different theories and strength criteria. In most cases the resistance criterion refers to the shear strength of the confined wall, as given below: 
a. Argentinean code Inpres-Cirsoc (1983):

$\tau=0.6 \tau_{m 0}+0.3 \sigma_{0}$

where $\tau_{m 0}$ is the masonry diagonal shear strength and $\sigma_{0}$ is the normal stress on the wall;

b. D’Amore and Decanini (1994):

$\tau=\left(0.6 \tau_{m 0}+0.3 \sigma_{0}\right) \cdot K_{t}$ with $K_{t}=\min (1.2-0.2 H / L, 1)$

where $K_{t}$ is a correction factor related with the wall aspect ratio;

c. Moroni et al. (1996):

$\tau=0.45 \tau_{m 0}+0.3 \sigma_{0}$

d. Turnšek and Čačovič (1970):

$\tau=\frac{0.7336 \tau_{m 0}}{b} \sqrt{\frac{\sigma_{0}}{0.7336 \tau_{m 0}}+1}$ with $b=\min (H / L, 1.5) \geq 1 ;$

where $b$ is a factor related with the distribution of shear stresses in the wall section;

e. Tomaževič and Klemenc (1997):

$\tau=\frac{0.7336 \tau_{m 0}}{b} \cdot\left(\frac{H / L}{2 \cdot \alpha \cdot b}+\sqrt{\left(\frac{H / L}{2 \cdot \alpha \cdot b}\right)^{2}+1+\frac{\sigma_{0}}{0.7336 \tau_{m 0}}}\right)$ with $\alpha=5 / 4 ;$

where $\alpha$ is a factor related with the distribution of interaction forces between the masonry panel and the confining elements;

f. Lafuente et al. (1998):

$$
\tau=0.7336 \tau_{m 0} \cdot \frac{a}{L} \cdot\left(H / L+\sqrt{H / L+4+4 \cdot \frac{\sigma_{0}}{0.7336 \tau_{m 0}}}\right)
$$

where $a / L$ is the ratio between a adherence factor and the wall length, with a value obtained interpolating between $0.56,0.65$ and 0.85 respectively for $H / L$ values of $1.21,1.01$ and 0.76 ;

g. Riahi et al. (2009):

$$
\tau=0.21 \tau_{m 0}+0.363 \sigma_{0}+0.0141 \sqrt{r \cdot f_{y} \cdot f_{c}}
$$

where $r$ is the longitudinal reinforcement ratio in the columns, $f_{y}$ is the steel yielding stress and $f_{c}$ is the concrete compressive strength. 
The models proposed in the Argentinean code (Inpres-Cirsoc 1983) and by Moroni et al. (1996) were established assuming a Mohr-Coulomb approach adjusted by minimum squares to experimental results obtained by the proponents. The model by D'Amore and Decanini (1994) was based in the Argentinean code, while introducing a correction factor to account for the aspect ratio of the wall. The model proposed by Turnšek and Čačovič (1970) is based on the stress condition at the center of the wall. Failure occurs when the principal stress reaches the value of the masonry tensile strength, which is related with the diagonal shear strength. The same criterion is adopted by Tomaževič and Klemenc (1997), considering the effect of the interaction forces between the masonry panel and the confining elements in the compressive stresses of the panel. The model proposed by Lafuente et al. (1998) is inspired in that of Tomaževič and Klemenc (1997), adapted to approximate the experimental results obtained by the proponents. In this case, a factor is considered to account the fraction of the wall subjected to diagonal compression, computed as the relation between an adherence measure and the wall length.

The model proposed by Riahi et al. (2009) was derived from a statistical analysis of a large database of lateral loading tests on CM walls, where a semi-empirical approach was derived through a linear regression analysis. The database was subjected to a process of eliminating outliers, but it needs to be noted that some particular cases were not considered in the database (e.g., walls with aspect ratio larger than 1.2) and that in many cases low-quality masonry units were used in the construction of the tested CM walls. The proposed model considers also a strength contribution from the dowel action of the longitudinal reinforcement bars in the columns, also considered by Tomaževič (1999) and Bourzam et al. (2008).

From the above, it is possible to state that the contribution of the column reinforcement to the strength of confined walls is one aspect requiring clarification. Contrarily to a RC frame system, where the steel works in tension due to flexure of the columns, in the case of CM walls, which present mostly shear deformation, the reinforcement provides mainly shear capacity. This strength is only mobilized for high levels of deformation and degradation of the columns, which then represents mainly an additional capacity reserve (Flores et al. 1996; San Bartolomé 1994; Zepeda et al. 2000). In particular, the dowel action of the longitudinal reinforcement bars balances the loss of shear strength in the masonry panel, keeping the lateral strength necessary for a ductile response. 


\subsection{Data mining models}

Here, taking into account the lack of agreement in the existing strength criteria for CM walls, a data mining (DM) process is applied to available experimental data. DM is a procedure developed in the field of computational intelligence, which aims to extract high-level knowledge from raw data (Witten and Frank 2005). This process has been applied in several areas, from medicine to business, but also in structural engineering (e.g., Marques et al. 2009). DM is based on an advanced analysis of databases through the application of methods developed by analogy to natural learning processes, such as neural networks. Then, by using a learning machine algorithm, several models can be adjusted to predict the value of an outputvariable, as a function of its influencing characteristics (input-variables).

Here, DM is applied for prediction of the shear strength of CM walls subjected to lateral loading. The database was created from a bibliographic review made in Marques (2012) on results from 105 tested walls, where the following variables were considered: normal stress on the wall, $\sigma_{0}$; masonry diagonal shear strength, $\tau_{m 0}$; wall slenderness given by its height to length ratio, $H / L$; masonry panel cross-section area ratio given by the relation between masonry panel area and total wall area, $A_{m} / A_{t}$; column longitudinal reinforcement ratio given by the relation between cross section of reinforcement and cross section of the vertical confining elements, $r$; and wall experimental maximum overall shear strength, $\tau_{\text {exp }}$. The matrix in Fig. 1 presents through a point cloud the values of the variables for the entire experimental database. As a general conclusion, the graphics apparently denote weak relations between variables, where the linear pattern of the masonry diagonal shear strength $\tau_{m 0}$ versus the wall experimental shear strength $\tau_{\exp }$ seems to be the exception. For this reason, a search of trends in the data was made adjusting models according to several techniques.

The DM process was performed using a library of algorithms created by Cortez (2010) in the $R$ tool environment (RDCT 2013). In addition to the traditional method of multiple regression (MR), nonparametric algorithms of regression trees (RT) and of k-nearest neighbors (KNN), and the nonlinear parametric techniques of artificial neural networks (ANN) and of support vector machines (SVM) were used. The evaluation scheme of each technique is based on ten runs of a five-fold cross validation, where the data are randomly divided in five partitions of equal size. Then, in each run and sequentially, each partition is used to test the model adjusted with the data in the remaining four partitions, in order to obtain, in each run, a prediction for all the data records. 


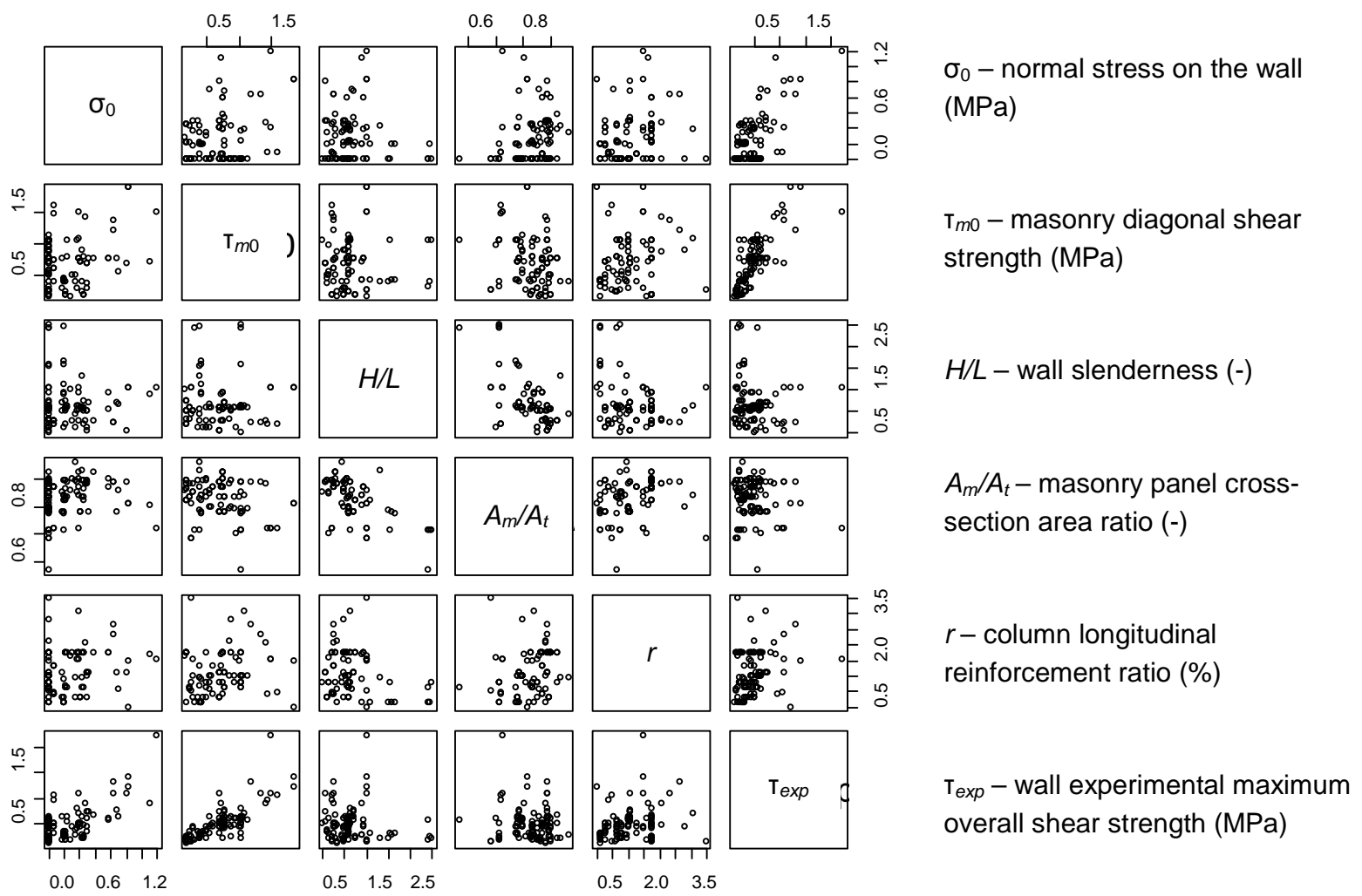

Fig. 1 Relationship matrix between the database variables

In the DM process, the best techniques in the prediction of the shear strength of confined walls under lateral loading were the MR and the SVM algorithms. In the case of the SVM, the input data are transformed to a higher $m$-dimensional feature space by using nonlinear mapping, and then the support vector machine finds the best linear separating hyperplane related to a set of support vectors in the feature space (Cortez 2010). This model uses a complex formulation, but the predictions are essentially based on a weighing computation under a set of support vectors founded in the transformed space. The prediction performance, according to a model of the wall experimental shear strength as a function of all the remaining variables in the database, is given by the dispersion graphs in Fig. 2a-e. The Pearson correlation coefficient (Cor) for each technique is averaged in all ten runs and includes a confidence interval using a student's t-test with a 95\% confidence level. A Cor value of 1 implies that the model describes the relationship between variables perfectly, whereas a value of 0 means that there is no correlation between the variables.

A sensitivity analysis to measure the input relevance was also made for the MR and SVM models adjusted to all data. Such quantification is determined by successively holding all of the inputs at a given baseline (e.g. their average values) while varying one input attribute through its full range of values. The results of the sensitivity analysis are presented in 
Fig. $2 \mathrm{~g}$, where the masonry diagonal shear strength $\left(\tau_{m 0}\right)$ is the more determinant variable for the CM wall shear strength, even if the normal stress $\left(\sigma_{0}\right)$ also presents a significant influence. It is noted that the sensitivity analysis for the MR model provides an insignificant influence of the column longitudinal reinforcement ratio for the prediction of the confined wall shear strength. For the SVM model, the column longitudinal reinforcement ratio $(r)$ has some low relevance. This can indicate a nonlinear influence of the $r$ variable in the CM wall shear strength, as proposed by D’Amore and Decanini (1994).

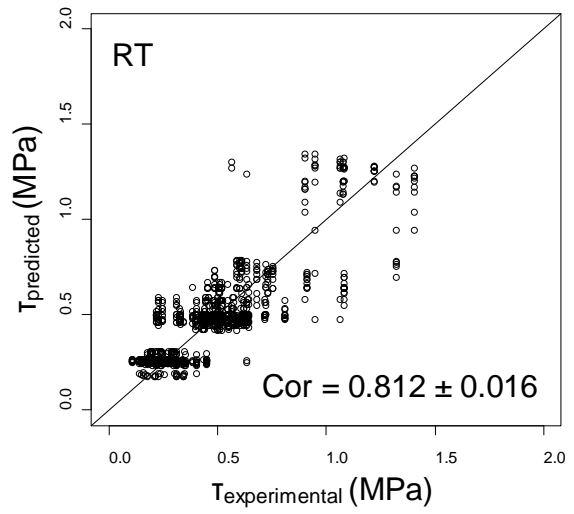

(a)

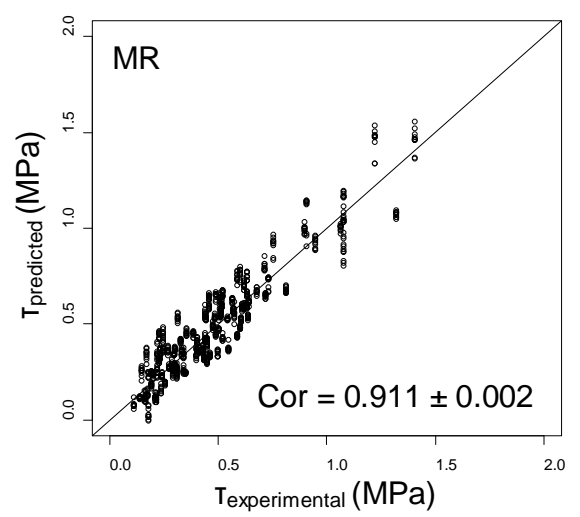

(d)

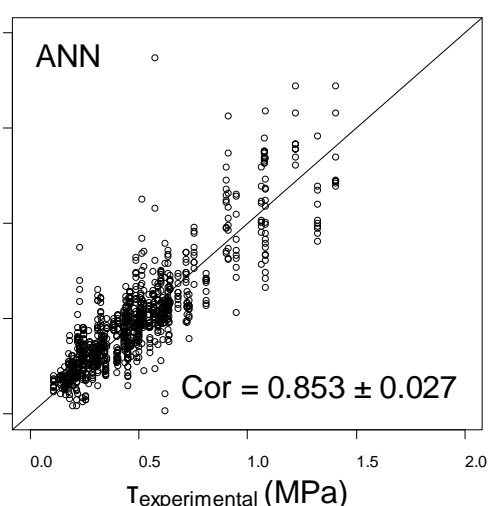

(b)

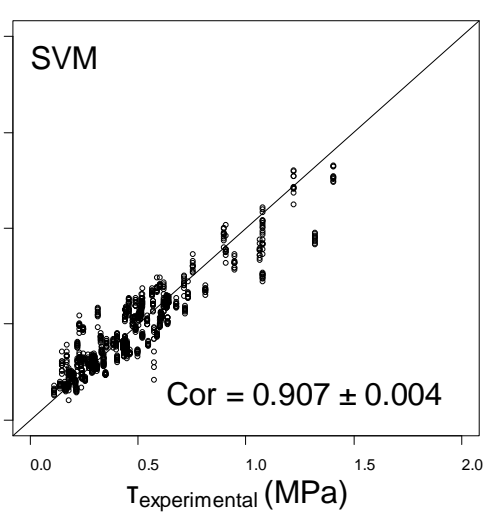

(e)

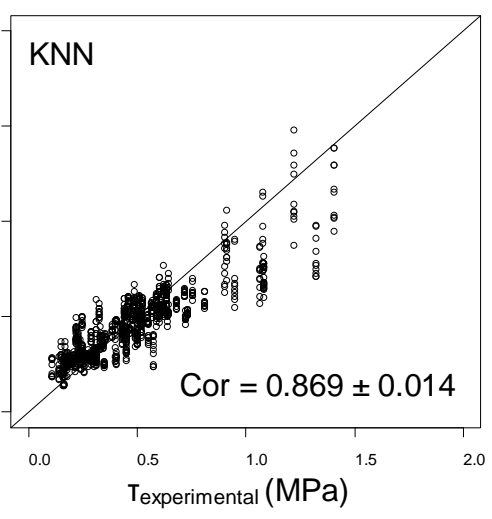

(c)

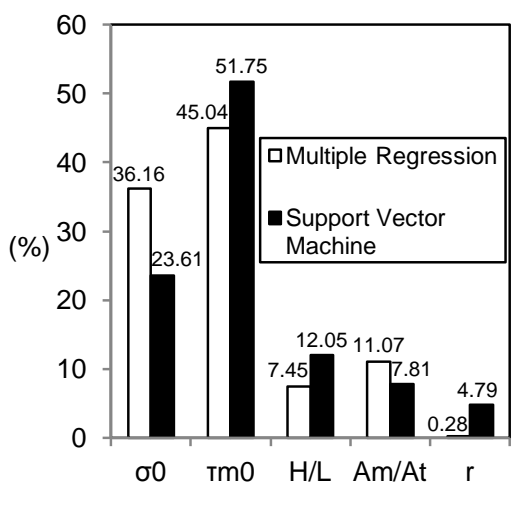

(f)

Fig. 2 Experimental versus predicted shear strength of CM walls by models of a regression tree, $\mathbf{b}$ neural network, $\mathbf{c}$ k-nearest neighbor, $\mathbf{d}$ multiple regression, e support vector machine; f importance of variables in the prediction with the MR and SVM models

The MR formula best fitted for the collected data is given in Eq. (8), which is independent of the column longitudinal reinforcement ratio. In this model for the CM wall shear strength, the constant coefficient presents a large value (1.0 MPa), even if it vanishes for ratio $A_{m} / A_{t}$ equals to one. 
$\tau=1.0072+0.4897 \tau_{m 0}+0.5341 \sigma_{0}-0.137 \mathrm{H} / L-0.9966 A_{m} / A_{t} \quad[\mathrm{MPa}]$

The SVM model is not formally presented, since it uses a formulation that can only be computationally solved through a complex algorithm. This model is the one that presents the best prediction for the CM wall shear strength, as given in Fig. 3, where the several existing models (presented in Sect. 2.1) and those proposed are compared using scatter plots of the predicted versus the experimental shear strength values for all records in the collected database. The MR formula presents also a good performance, and given its simplicity, is strongly recommended for design purposes.
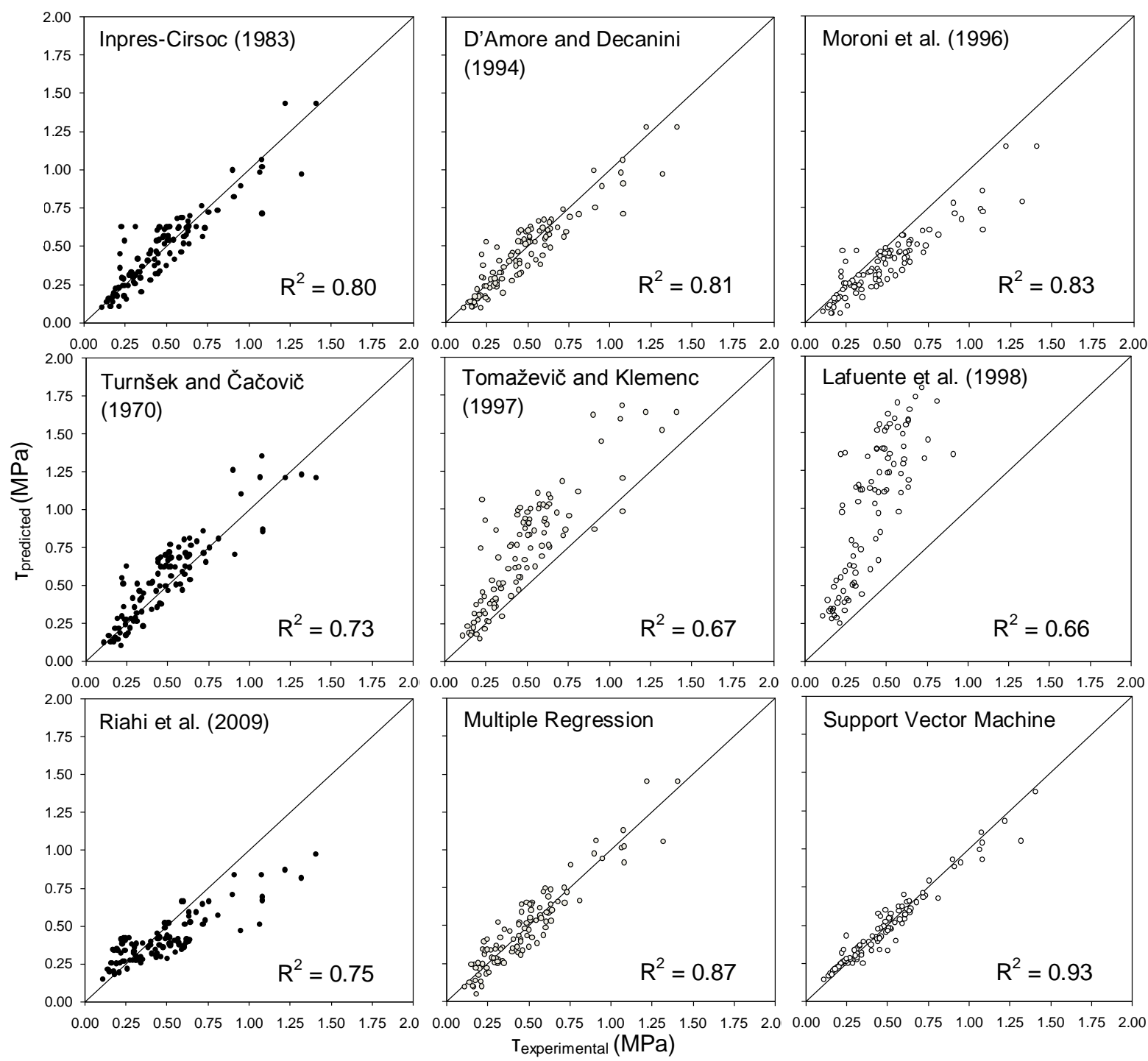

Fig. 3 Experimental versus predicted shear strength of CM walls according to several models 


\section{An analytical model for pushover analysis}

The occurrence of recent seismic events, such as El Salvador (EERI 2001) and Chile (Brzev et al. 2010) earthquakes, allowed the identification of typical damage and deformation mechanisms in CM buildings. In many cases, the seismic response was controlled by inadequate design of the structures (San Bartolomé 2007), but typical patterns are observed, consisting mainly of in-plane diagonal cracking failure of walls and development of first storey mechanisms (Fig. 4a). The observed damage occurs in some cases at upper storeys of the buildings, with associated out-of-plane damage, and is mostly due to absence of box behavior in the affected storeys. Brzev et al. (2010) attributes the seismic damage on buildings mainly to inadequate wall density, poor quality of masonry and construction, deficiencies in detailing of RC confining elements, absence of confinements at openings, and geotechnical issues.

Some experimental studies have been also carried out on three-dimensional CM structures. San Bartolomé (1994) tested 2- and 3-levels CM structures with only two parallel walls in the loading direction, both monotonically and in shaking table. Alcocer et al. (2004) tested 1-to-3 storey half-scale CM buildings with similar plan configurations in shaking table, with the 2- and 3-storey buildings being presented in Fig. 4b. In these cases, deformations and damage are concentrated at the first storey, resulting in a shear-governed storey mechanism. It is also noted that a decrease of the first storey maximum drift seems to occur with increasing elevation of the structure. A similar response to that described before is observed for the 3storey building models tested by Tomaževič (2007) and Shahzada et al. (2011) in a shaking table, although with structures presenting different masonry characteristics and cross sections of the confining elements. Zavala et al. (2004) tested under quasi-static loading a CM building made of handmade clay bricks. In this case, the structure behaved elastically until a $0.06 \%$ first storey drift and the diagonal cracking started for $0.12 \%$ drift. Afterwards, a large degradation of the walls is observed for $0.5 \%$ drift with maximum damage occurring for $1.33 \%$ drift.

As evidenced from post-earthquake observation and experimental simulation, CM structures present a complex behavior when subjected to lateral cyclic loading, particularly because of the interaction between masonry and the confining elements in individual walls, and also due to the coupling effect that the beam-slab couple provides to adjoining confined walls. Then, more than a method to compute the exact response of CM buildings, a simplified 
model to compute and evaluate globally the relevant variables for the seismic assessment of CM structures is presented next.
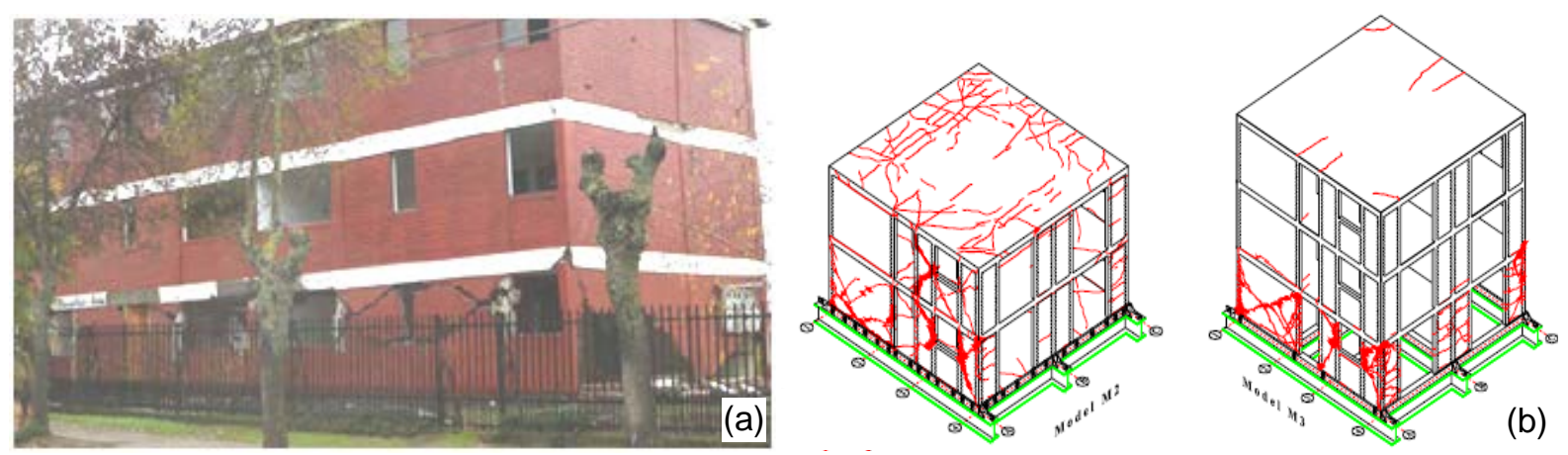

Fig. 4 Damaged buildings in a 2010 Chile earthquake (Brzev et al. 2010) and b shaking table tests (Barragán and Alcocer 2006)

\subsection{Proposed method}

The proposal bases on the extension to confined masonry of a method originally implemented by Marques (2012) for unreinforced masonry structures, the "RANm", which uses an incremental-iterative procedure with force control and is based on the original work of Augenti (2004). The method assumes that each storey of a building is constituted by individual confined masonry walls, which can be hypothesized as one-dimensional equivalent wide-column elements of constant thickness that deform in a double curvature condition (Fig. 5a). The wide-column vertical axis is coincident with the vertical barycentric axis of the corresponding wall, which is assumed with its real cross-section for computation purposes. The confined walls in each storey are assumed to be connected by beams infinitely rigid and infinitely resistant, meaning that they present an equal displacement at the top.

Regarding the diagonal cracking failure, the reference value for computation of the strength domain of CM walls is the maximum shear strength $v_{\max }$, given by Eq. (8), and assuming a trilinear backbone response for the walls that considers cracking, maximum and ultimate limits (“original response” in Fig. 5b). The drifts are computed as proposed by Rihai et al. (2009):

$$
\delta_{c r}=\gamma \frac{v_{c r}}{\sqrt{f_{m}}}
$$

with $\gamma=1.13$ and 0.72 respectively for ceramic brick and concrete block masonry, and where $f_{m}$ is the masonry compressive strength; 
$\delta_{u l t}=\mu \gamma \frac{v_{\max }}{\sqrt{f_{m}}}$, with the ductility factor computed as $\mu=\frac{0.5}{v_{\max }^{2}}+1.3 \leq 6$;

$\delta_{\text {max }}=0.65 \delta_{u l t}$.

Note that the strength domain is dependent on the axial load $N$ on the confined wall, both in terms of shear load and drift, and is updated for each variation of axial load due to the lateral loading. This variation is computed as a function of the wall's relative stiffness according to a scheme presented in Marques and Lourenço (2011). The change in the strength domain of a confined wall is exemplified in Fig. 5, due to decompression (reduction of axial load) and over-compression (increase of axial load). The figure is merely illustrative and, due to the adaptive incremental procedure, the wall response presents a complex shape defined through the strength points $(V-\delta)$ computed in the successive steps.

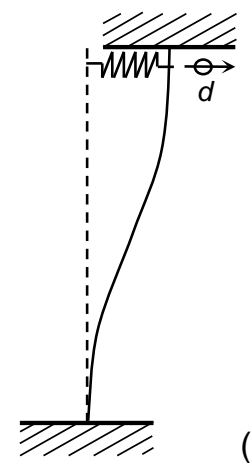

(a)

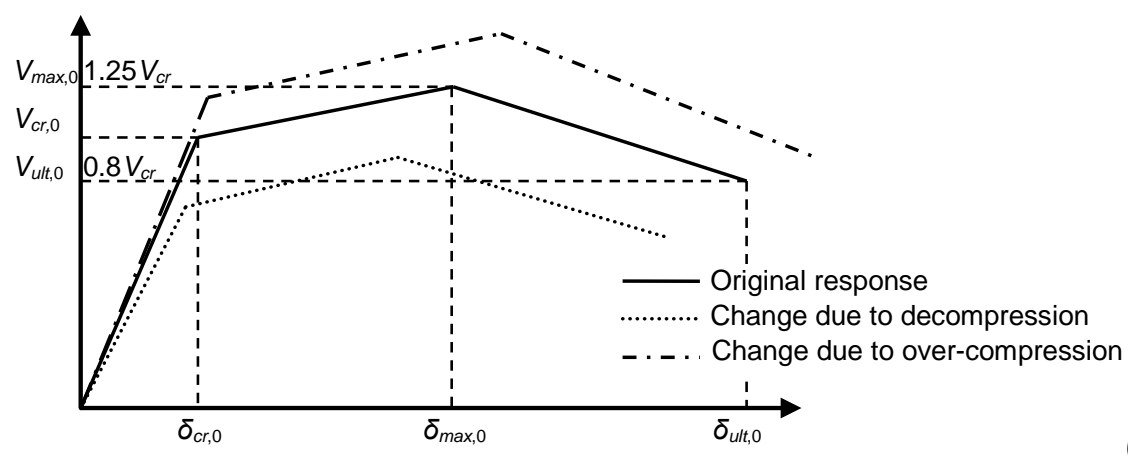

Fig. 5 Illustration of a the equivalent wide-column element and $\mathbf{b}$ alteration in the strength domain of CM wall due to decompression and over-compression

The procedure is implemented by monitoring the shear load and drift in each wall. In each step of horizontal loading, and for each wall, a comparison is made between the applied shear load and the limit value each condition in the trilinear backbone response. Accordingly, in each loading step the drift value of the walls is computed trough the expression defined for the applicable condition. Monitoring also controls wall failures, which are in general assumed by diagonal cracking. Walls under tension evolve to a decompression state with subsequent transfer of axial and shear loads to the confining columns. The diagonal cracking sequence for the walls is controlled throughout the limit drifts according to the assumed backbone shear response, which are updated at each loading step. The decompression state of a wall is 
identified, independently of the response condition and drift, when its resultant axial load is equal to zero, and after that the drift is influenced by the residual shear strength in the columns.

As a sequence of the incremental procedure, after full decompression $(\mathrm{N}=0)$ of a confined wall, its shear strength presents a residual value. This residual strength is considered to be only the shear contribution of the columns by the dowel action of the reinforcement bars, computed according to the respective fraction in Eq. (7) by Riahi et al. (2009), and adapted to account for the slenderness of the wall, as:

$$
\tau=0.0141 \sqrt{r \cdot f_{y} \cdot f_{c}} \cdot \min (L / H, 1)
$$

where $r$ is the longitudinal reinforcement ratio in the columns, $f_{y}$ is the steel yield stress and $f_{c}$ is the concrete compressive strength. More sophisticated models for the residual strength of CM walls can be found in Ranjbaran et al. (2012). In this way, a confined wall after its full decompression sustains a lower strength, although the base shear of the structure is allowed to increase after redistribution of shear loads for the remaining walls.

After reaching the last displacement supported by the decompressed wall, a drop is observed in the base shear strength of the structure, even if in general the remaining walls are in the first cracking stage at the first storey and in elastic phase in the elevated storeys. After the collapse of the decompressed wall, a redistribution of internal forces in the structure is still possible, namely in terms of the vertical loading. Figure 6 illustrates an equilibrium scheme based on the approach implemented by Marques (2012) after restart of the lateral incremental loading.

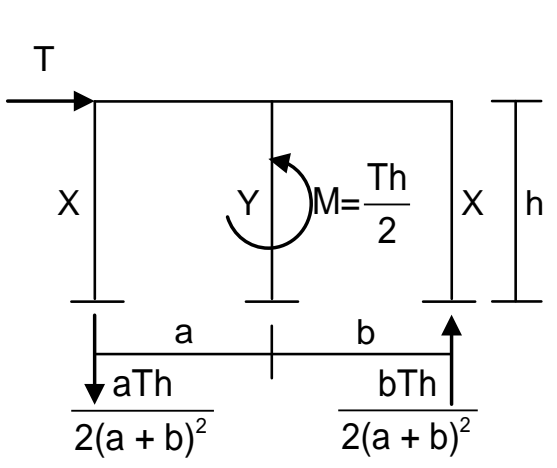

(a)

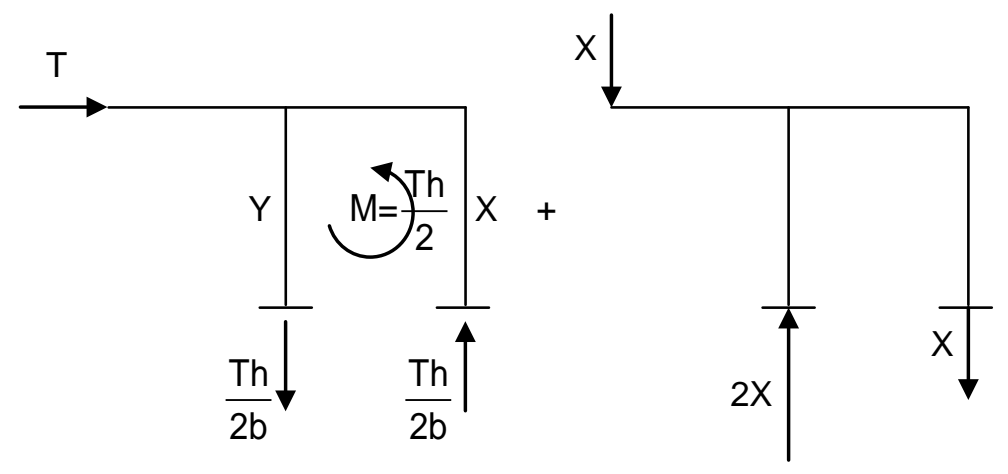

(b)

Fig. 6 Static equilibrium of structure and loads in the equivalent wide-columns a before and b after an element collapse 
The ultimate displacement for each individual wall is, in general, the ultimate drift in the last condition of the assumed backbone shear response. This limit drift is only applicable for walls under tension, since the compressed walls remain normally in elastic stage at that point. Subsequently, after collapse of a wall reaching its ultimate drift, the possibility of reequilibrium to the structure is validated. If equilibrium is possible the procedure continues until a new wall fails. Otherwise, the computation is stopped defining the ultimate displacement of the entire structure. A flowchart synthesizing the proposed method is presented in Fig. 7 and a more comprehensive description is given in the following section.

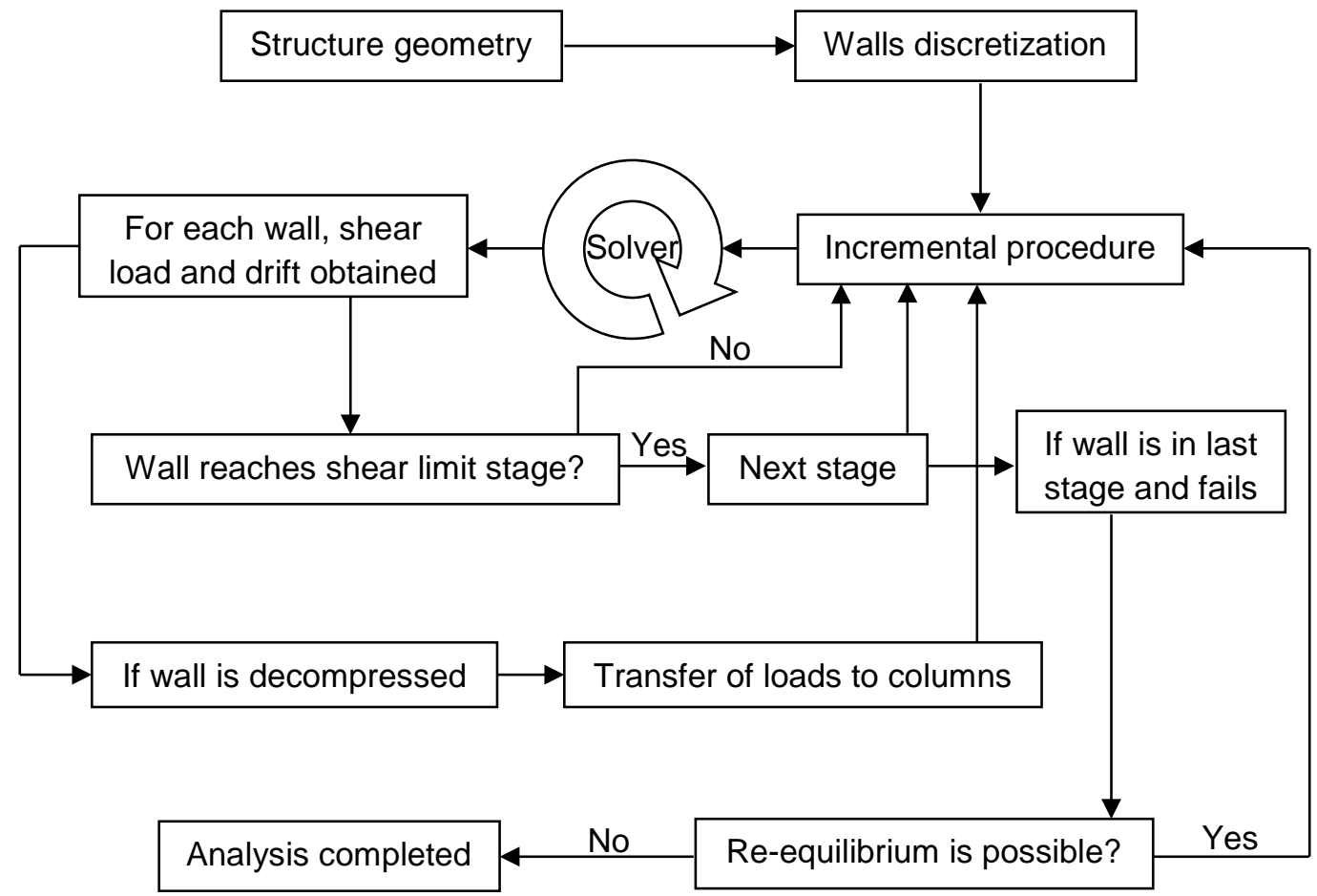

Fig. 7 Flowchart describing generically the proposed method

\subsection{Results obtained by the proposed method}

The idealized model is here applied referring to an experimental case. The case study is a tridimensional CM structure constituted by two identical longitudinal walls and two solid transversal walls (Fig. 8a), the structure being tested by Alcocer et al. (1993) at CENAPRED (Mexican Center for Disaster Prevention) under lateral cyclic loading distributed proportionally to the structure height. The structural system consists of ceramic brick masonry panels which are confined by RC elements, as presented in Fig. 8b. The floor scheme is a reinforced concrete slab anchored to the RC beams. The masonry properties, which were 
obtained from tests, are a compressive strength of $5.3 \mathrm{MPa}$, a diagonal shear strength of 0.59 MPa, an elastic modulus of $1495 \mathrm{MPa}$ and a shear modulus of $911 \mathrm{MPa}$.

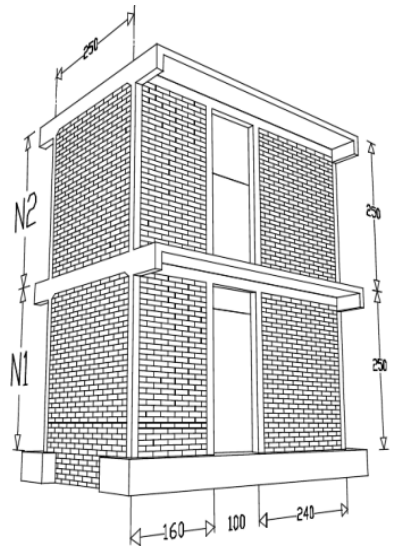

(a)

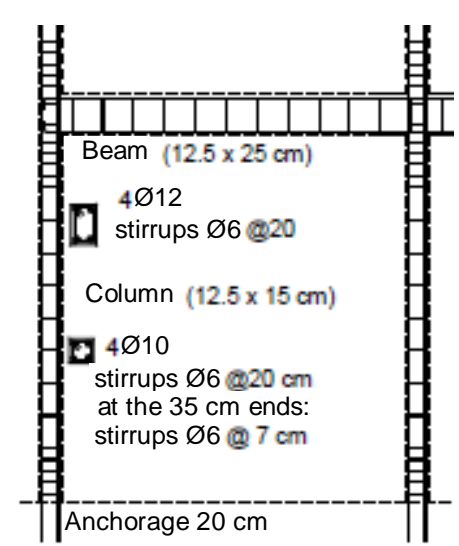

(b)

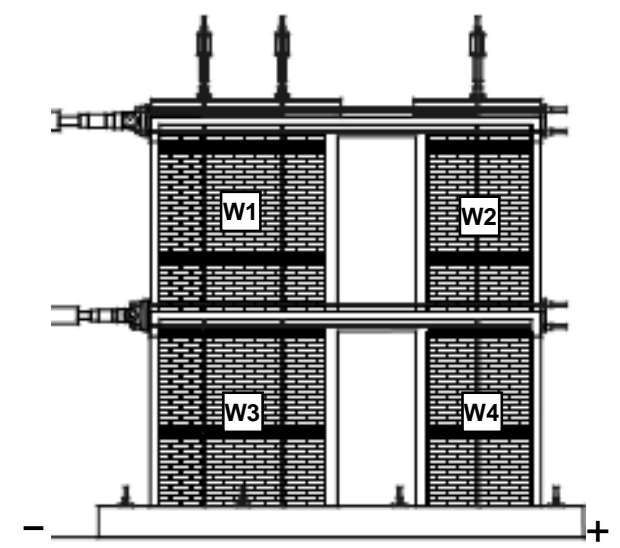

(c)

Fig. 8 CM structure tested at CENAPRED by Alcocer et al. (1993): a 3D view; b reinforcement details; $\mathbf{b}$ test setup

In the test, the gravitational loads were simulated through the application of six steel tie-rods anchored on the top slab, subjecting the first level walls to a stress of $0.49 \mathrm{MPa}$. The lateral loads were applied through four hydraulic actuators of reverse action, as presented in Fig. 8c. According to Sánchez et al. (1996), the first diagonal cracks in the masonry occurred in the first level walls for a base shear of $337 \mathrm{kN}$ and a storey drift of $0.12 \%$. Then, a concentration of damage in the first level is observed, mainly due to diagonal cracking. The diffusion of the diagonal cracks to the columns occurred for distortions of about $0.4 \%$ in the first level. In the end of the test, these RC elements presented spalling of the concrete and buckling of the longitudinal steel bars, failing by shear and causing the collapse of the structure.

The longitudinal walls present two levels of a pair of CM panels made of ceramic brick with $0.125 \mathrm{~m}$ thickness, which are connected at the top by an RC beam (Fig. 9). The adopted geometrical model for the walls (transformed into a single wall) is then constituted, in each level, by two wide-columns with a deformable height of $2.25 \mathrm{~m}$ connected by a rigid lintel with $0.25 \mathrm{~m}$ height. The vertical loading in the structure induces the following initial axial loads on the confined longitudinal walls: $R_{\mathrm{W} 1}=234.4 \mathrm{kN}, R_{\mathrm{W} 2}=152.8 \mathrm{kN}, R_{\mathrm{W} 3}=294.4$ $\mathrm{kN}, R_{\mathrm{W} 4}=196.2 \mathrm{kN}$. The test is conducted with a lateral load distributed proportionally to the structure height, which is consistent with the "shear type" deformation mode observed for CM structures. Therefore, the structure is subjected at the top of the first and second storeys 
respectively to $1 / 3$ and $2 / 3$ of the base shear load. The incremental-iterative computation is made to simulate the loading in positive sense (left to right), by solving in each step the minimization expression, detailed in Marques and Lourenço (2011):

$$
\min \left(\sum_{i=1}^{m}\left|\sum_{j=1}^{n} V_{i, j}-T_{i}\right|+f_{n r} \cdot \sum_{i=1}^{m} \sum_{j=1}^{n-1}\left|\delta_{i, j}-\delta_{i, j+1}\right|\right)
$$

where $V_{i, j}$ is the shear load on the wall $j$ of storey $i ; T_{i}$ is the shear load applied to storey $i$, which is cumulative from the up to the bottom storeys; $f_{n r}$ is a scaling factor between load and displacement computed differences; and $\delta_{i, j}$ is the top displacement of the wall $j$ in storey $i$.
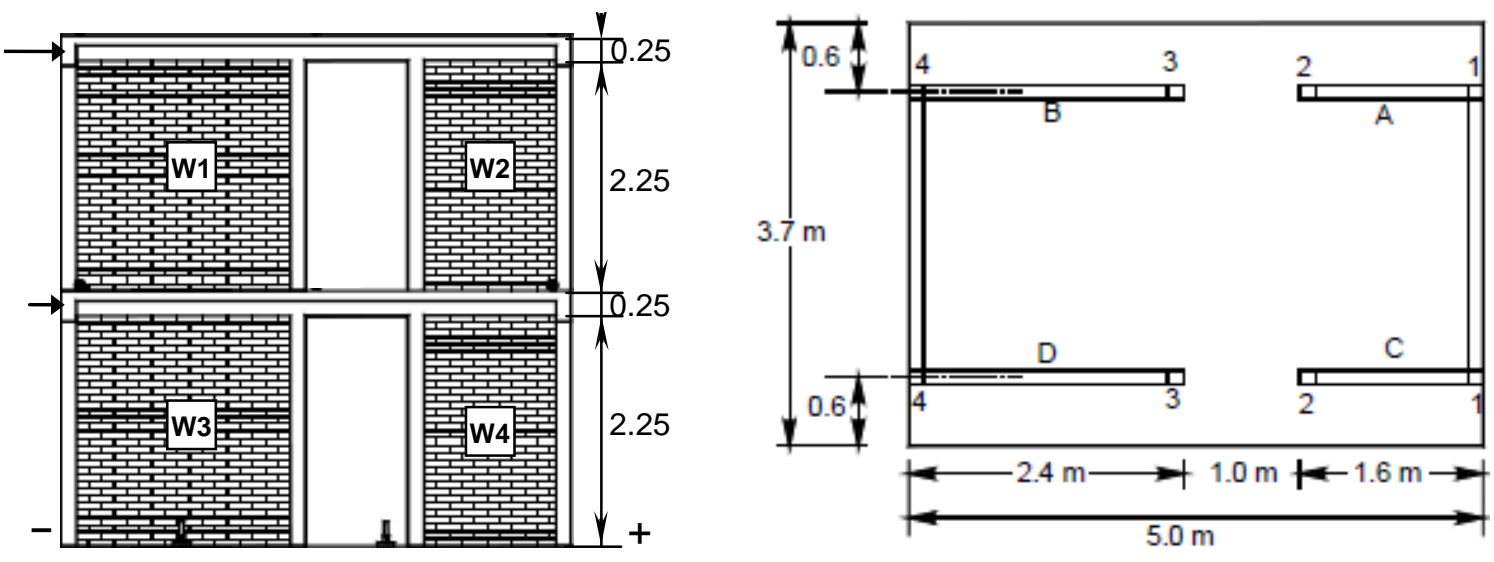

Fig. 9 Front and plan views of the structure tested by Alcocer et al. (1993)

In the structural analysis, the two longitudinal walls behaved elastically until a base shear of about $280.0 \mathrm{kN}$, after which Wall 3 starts cracking. For a base shear of $302.6 \mathrm{kN}$ this wall is totally decompressed, with a load transfer to the confining columns. Then, in correspondence with a base shear of $303.0 \mathrm{kN}$, Wall 3 presents a decrease in capacity, until its failure for a drift of $0.41 \%$. Note that load redistribution of the structure after failure of Wall 3 is not possible, because only one wall remains in the first level. The capacity curves of the structure are given in Fig. 10, where a horizontal branch is observed due to the transfer of shear load in Wall 3 for the neighboring confining elements. Additionally, Figure 11 shows the evolution of axial and shear loads in the confined walls of the first level. The axial load varies with symmetric complex trends for Walls 3 and 4 due respectively to tension and compression states, evolution that induces correspondingly elastic-cracked and continuouselastic responses in Walls 3 and 4.

A comparison is made next between the experimental test, the predictions by the proposed method and the predictions from a model created in the 3DMacro computer code 
(Gruppo Sismica 2013) which is based on the discrete element approach developed by Caliò et al. (2012).

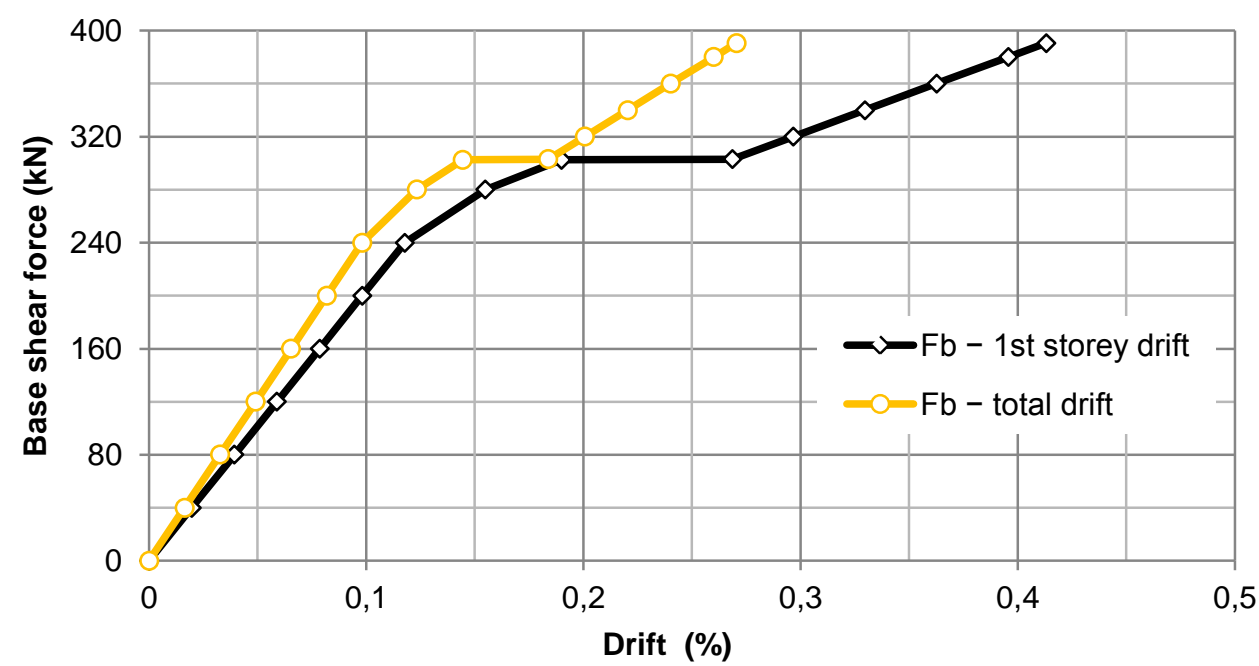

Fig. 10 Capacity curves corresponding to the loading in positive sense
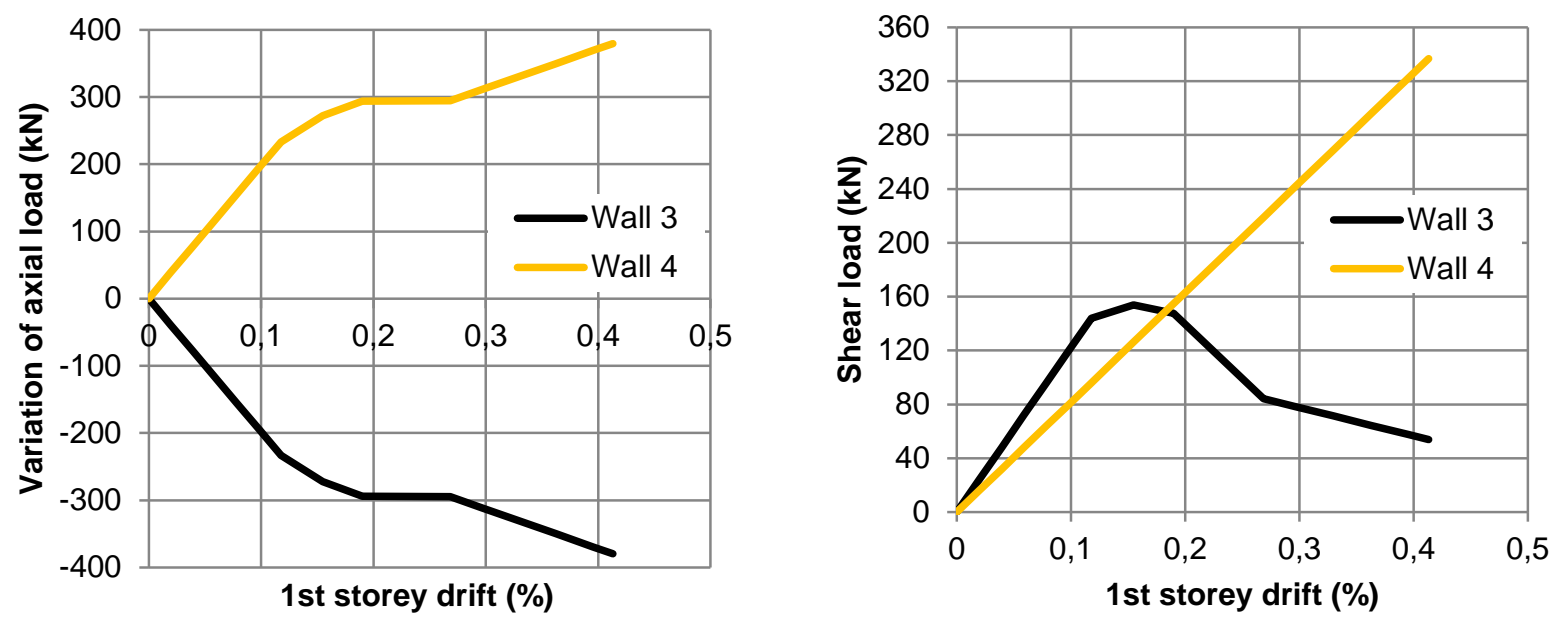

Fig. 11 Evolution of axial and shear loads in the confined walls of the first level

\subsection{Comparison of results}

The computational model created in 3DMacro of the CM structure tested by Alcocer et al. (1993) is presented in Fig. 12a, using a discretization of masonry panels (modeled as articulated quadrilaterals with rigid edges crossed by two diagonal springs and presenting interface distributions of springs in the sides) and confining columns and beams (modeled as nonlinear beam finite elements with concentrated plasticity). Based on the pushover analysis, in Fig. 12b-c the predicted and the experimental damages are confronted, and in Fig. 12d the 
predicted envelopes by the proposed method and from 3DMacro are compared against the experimental response. The prediction in 3DMacro allows generally to identify the masonry panels affected by diagonal cracking, and also the critical segments of the confining elements. Regarding the loading envelopes, the 3DMacro provides a good estimation for the initial stiffness and for the base shear strength, although the ductility is overestimated. In the case of the proposed method, the prediction could only be made until a limited deformation, but with a very satisfactory approximation.

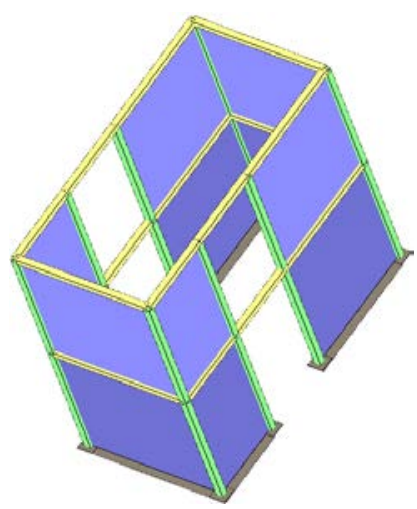

(a)

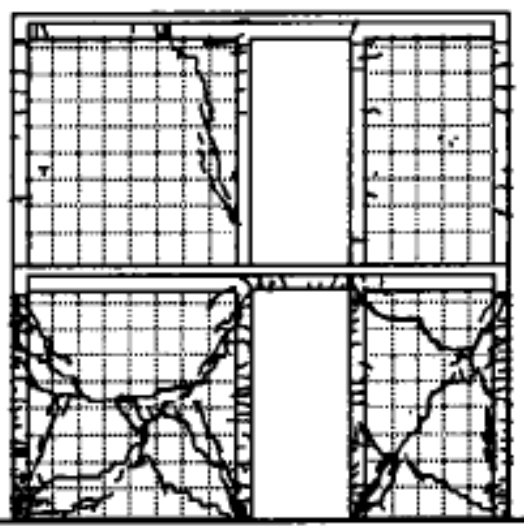

(c)

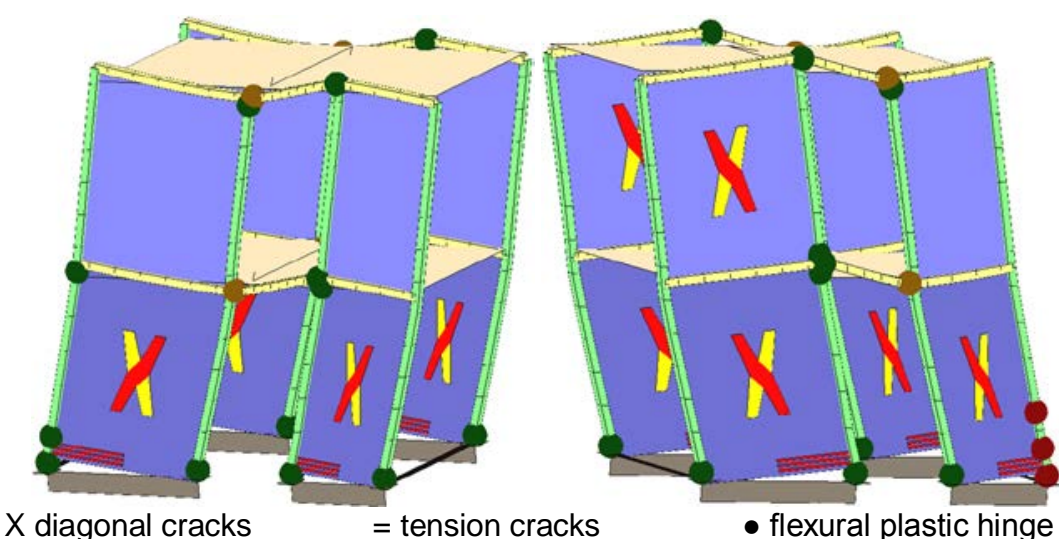

(b)

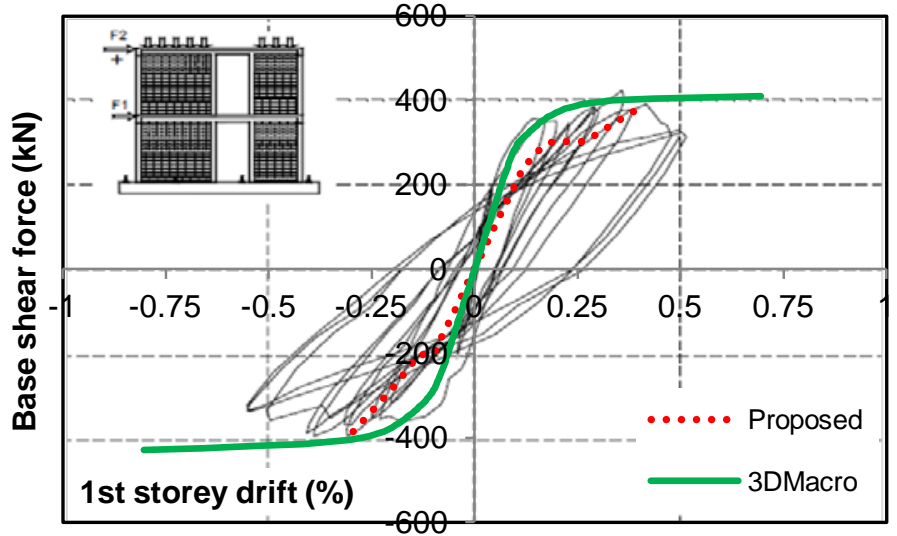

(d)

Fig. 12 Loading simulation: a 3DMacro model; b predicted damage and c observed damage for $0.5 \%$ drift; $\mathbf{d}$ comparison of predicted envelopes with experimental response

Based on the modeling in 3DMacro, Figure 13 presents the stresses in the confinements-masonry interface, for the positive and negative loading senses and corresponding to a $0.1 \%$ drift of the first level. The stress evolution influences the loading on elements, namely the axial load on the masonry panels, which produces a variation in the strength domain. However, in the graph in Fig. 14, which corresponds to the negative loading sign, it can be observed that a low variation of the axial load on panels occurs in the initial 
stage of loading. From this graph, it can also be concluded that the evolution of the compression and decompression states computed according to the proposed method for Walls 3 and 4 (note that loads are divided by two to uncouple the two longitudinal walls), is comparable to the variation obtained for the 3DMacro model of the sum of axial load on the panel and on the confining column with the analogous stress (compression or tension).
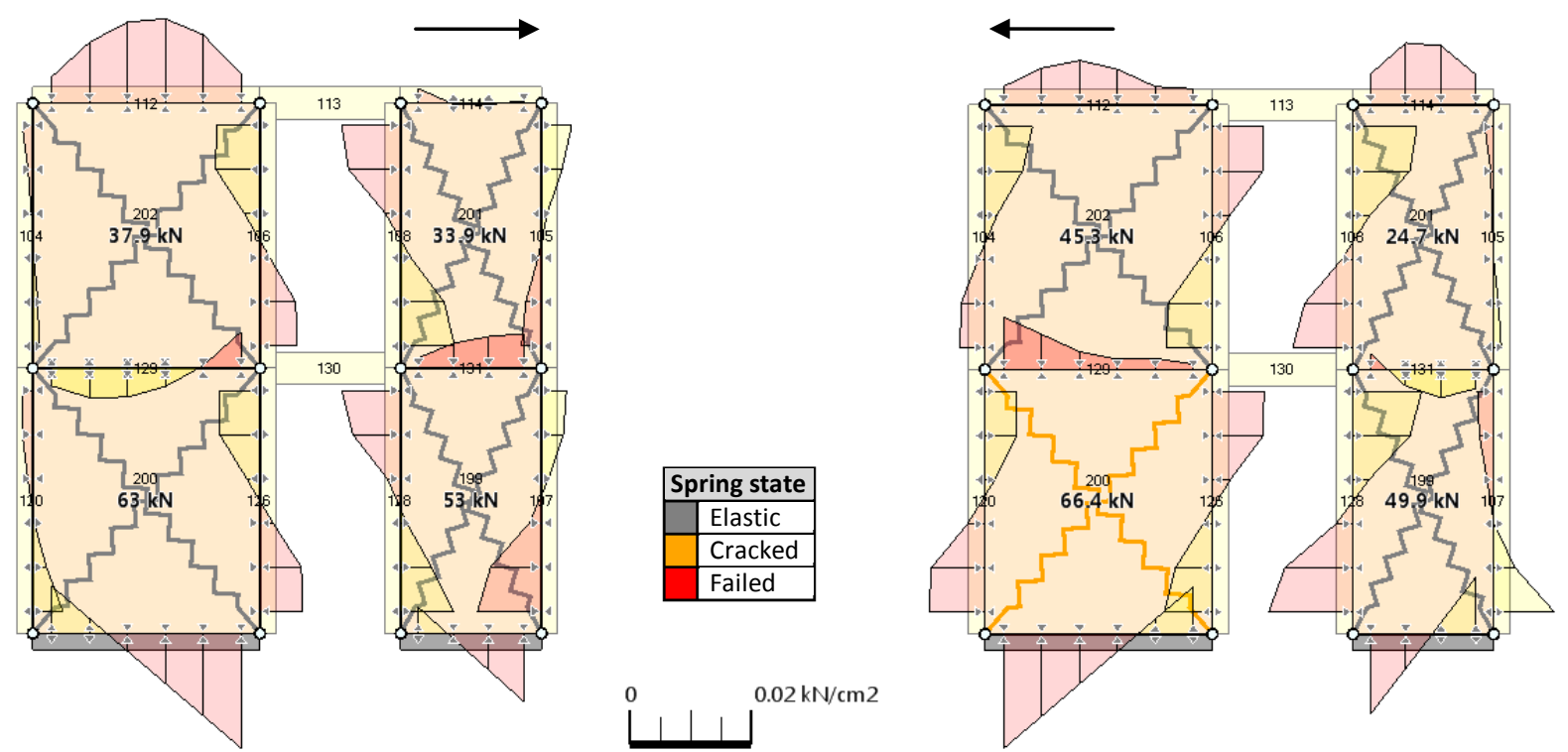

Fig. 13 Stresses in the confinements-masonry interface for positive and negative loadings, corresponding to a $0.1 \%$ drift of the first level

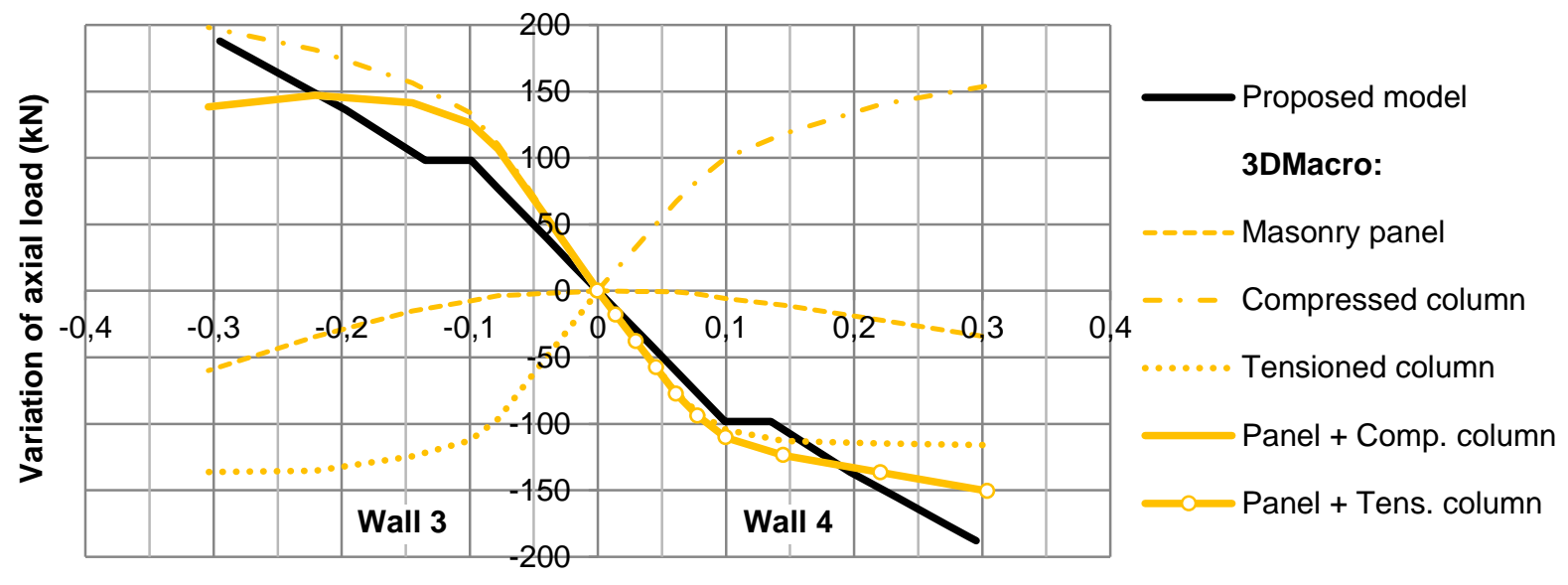

1st storey drift (\%)

Fig. 14 Evolution of axial loads in the confined walls of the first level, for negative loading

Finally, the evolution of the shear load on confined walls and masonry panels in the first level of the structure is presented in Fig. 15, respectively for the proposed method and for the 3DMacro model and considering both signs of loading. If in the case of the proposed 
method the walls with major contribution for the base shear capacity of the structure are those subjected to higher compression, in the case of the 3DMacro model the Wall 3 is the one that presents the major strength contribution in both loading signs. This is due to the "shear type" deformation mode of the structure, according to which Wall 3 contributes more for the shear capacity, due to its larger length. Still, the global response of both models and the test results are in rather good agreement.

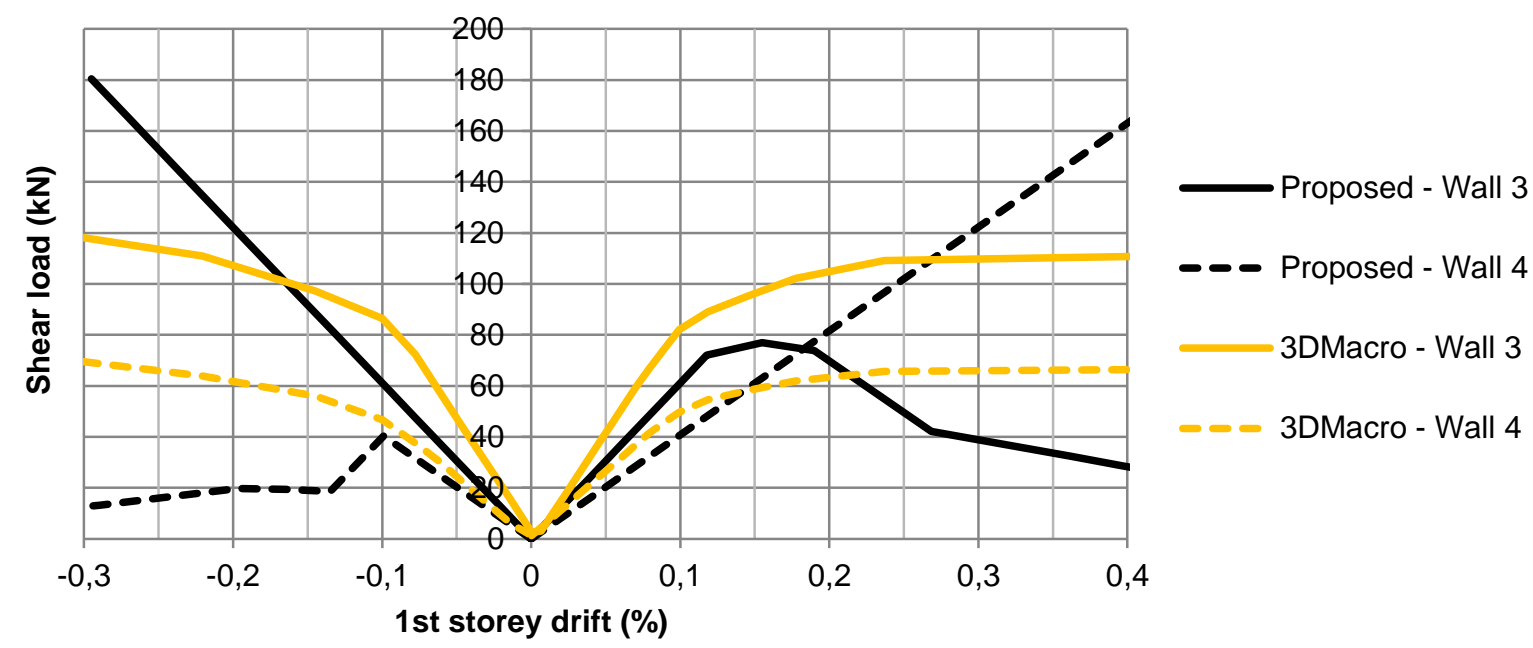

Fig. 15 Evolution of shear loads in the confined walls and masonry panels respectively for the proposed method and for the 3DMacro model

\section{Conclusions}

Confined masonry (CM) has been widely disseminated as an earthquake-resistant easy to build and inexpensive housing solution. Existing CM buildings designed without engineered rules or inadequate computation approaches presented an inadequate seismic response in recent earthquakes. For this reason, efforts have been made to contribute for a better practice in the design and construction of CM buildings.

Here, a comprehensive study regarding numerical and analytical modeling is made for single confined walls and complex CM buildings. In the first case, a data mining (DM) process is performed on a database of results collected from lateral loading tests on CM walls, to obtain adequate prediction models for the shear strength. The applied DM process allowed to obtain prediction models for the shear strength of CM walls more accurate than the existing formulas, according to linear (multiple regression) and nonlinear (support vector machine) models. The sensitivity analysis indicates that the masonry diagonal shear strength is crucial in the prediction of the shear strength of $\mathrm{CM}$ walls, whereas the column longitudinal 
reinforcement ratio has a small influence. The need to consider additional variables in the prediction is identified, such as the unit percentage of holes and a measure of the column-tomasonry connection.

Typical behavioral patterns of CM structures are identified from post-earthquake observation and experimental simulation, namely diagonal cracking propagation in walls from the masonry panel to the columns and the effect of a soft ground-storey where the damage is concentrated. Furthermore, a decrease of the inter-storey maximum drift seems to occur with the elevation of the structure. The need to provide a box behavior to the CM buildings is identified in mode to avoid out-of-plane failures and to allow then exploit the full in-plane strength of the confined wall assemblages.

Regarding the building global response, a simplified analytical approach is proposed which is based on the modeling with wide-column elements that present an adaptive shear load-displacement law. The proposed approach is validated against a discrete element model and the experimental results for a CM structure tested under quasi-static cyclic loading. The analytical simulation by the discrete element model provides a good estimation for the initial stiffness and for the base shear strength of the CM structure, although the ductility is overestimated. In the case of the proposed method, the capacity curve could only be computed up to a limited deformation, but with a very satisfactory approximation of the experimental envelope and ultimate capacity. Thus, both methods are able to be used in performance-based seismic assessment and design.

\section{Acknowledgements}

The first author acknowledges the financial support from the Portuguese Foundation for Science and Technology (FCT) through the Ph.D. grant SFRH/BD/41221/2007.

\section{References}

Alcocer SM, Sanchéz TA, Meli R (1993) Comportamiento de la estructura tridimensional de mampostería confinada de dos niveles del CENAPRED (Behavior of the two-level tridimensional confined masonry structure of CENAPRED). Report ES/01/93, Centro Nacional de Prevención de Desastres, Área de Ensayes Sísmicos, Mexico D.F. 
Alcocer SM, Arias JG, Vázquez A (2004) Response assessment of Mexican confined masonry structures through shaking table tests. In: Proceedings of the 13th World Conference on Earthquake Engineering, Vancouver, paper 2130

Augenti N (2004) Il calcolo sismico degli edifici in muratura (Seismic design of masonry buildings). UTET Libreria, Turin (in Italian)

Barrágan R, Alcocer SM (2006) Shaking table tests on half-scale models of confined masonry made of handmade solid clay bricks. In: Proceedings of the 1st European Conference on Earthquake Engineering and Seismology, Geneva, paper 1147

Bourzam A, Goto T, Myiajima M (2008) Shear capacity prediction of confined masonry walls subjected to cyclic lateral loading. Doboku Gakkai Ronbunshuu A 64(4):692-704. doi:10.2208/jsceja.64.692

Brzev S (2007) Earthquake-resistant confined masonry construction. National Information Center of Earthquake Engineering (NICEE), Kanpur

Brzev S, Astroza M, Moroni MO (2010) Performance of confined masonry buildings in the February 27, 2010 Chile earthquake. EERI Report, Earthquake Engineering Research Institute, California

Caliò I, Marletta M, Pantò B (2012) A new discrete element model for the evaluation of the seismic behaviour of unreinforced masonry buildings. Eng Struct 40:327-338. doi:10.1016/j.engstruct.2012.02.039

CEN (2005) Eurocode 8: Design of structures for earthquake resistance - Part 3: Assessment and retrofitting of buildings, EN 1998-3:2005. European Committee for Standardization, June 2005, Brussels

Cortez P (2010) Data mining with neural networks and support vector machines using the $\mathrm{R} / \mathrm{rminer}$ tool. In: Proceedings of the 10th Industrial Conference on Data Mining, Berlin, CD-ROM

D’Amore E, Decanini L (1994) Shear strength analysis of confined masonry panels under cyclic loads: Comparison between proposed expressions and experimental data. In: Proceedings of the 9th International Seminar on Earthquake Prognostics, San José

EERI (2001) Preliminary observations on the El Salvador earthquakes of January 13 and February 13, 2001. EERI Report, Earthquake Engineering Research Institute, California Fajfar P, Fischinger M (1988) N2 - a method for nonlinear seismic analysis of regular buildings. In: Proceedings of the 9th World Conference on Earthquake Engineering, Tokyo-Kyoto, vol. 5, pp 111-116 
Flores L, Alcocer SM (1996) Calculated response of confined masonry structures. In: Proceedings of the 11th World Conference on Earthquake Engineering, Acapulco, paper 1830

Gouveia JP, Lourenço PB (2007) Masonry shear walls subjected to cyclic loading: Influence of confinement and horizontal reinforcement. In: Proceedings of the 10th North American Masonry Conference, St. Louis, paper 042

Gruppo Sismica (2013) Theoretical manual of the 3DMacro software, beta version. Gruppo Sismica, Catania

Inpres-Cirsoc (1983) Argentinean code for earthquake-resistant constructions, Part III: Masonry buildings. INPRES, San Juan (in Spanish)

Jäger W, Schöps P (2009) Confined masonry - a chance to improve the load bearing capacity. In: Proceedings of the 11th Canadian Masonry Symposium, Toronto, CD-ROM

Lafuente M, Castilla E, Genatios C (1998) Experimental and analytical evaluation of the seismic resistant behaviour of masonry walls. Masonry International 11(3):80-88

Lourenço PB, Mendes N, Ramos LF, Oliveira DV (2011) Analysis of masonry structures without box behavior. International Journal of Architectural Heritage 5(4-5):369-382. doi:10.1080/15583058.2010.528824

Lourenço PB, Avila L, Vasconcelos G, Alves JP, Mendes N, Costa AC (2012) Experimental investigation on the seismic performance of masonry buildings using shaking table testing. Bull Earthquake Eng. doi:10.1007/s10518-012-9410-7

Marques R, Lourenço L, Barros J (2009) Data Mining techniques and UPV tests for the assessment of damage levels in concrete exposed to high temperatures and subject to compression. In: Proceedings of the 1st International Conference on Soft Computing Technology in Civil, Structural and Environmental Engineering, Funchal, paper 46

Marques R, Lourenço PB (2011) Possibilities and comparison of structural component models for the seismic assessment of modern unreinforced masonry buildings. Comput Struct 89(21-22):2079-2091. doi:10.1016/j.compstruc.2011.05.021

Marques R (2012) New methodologies for seismic design of unreinforced and confined masonry structures. Ph.D. thesis, University of Minho, Guimarães

Meli R, Zeevaert W, Esteva L (1968) Behaviour of reinforced masonry under alternating loads. Report N. 156, Instituto de Ingeniería, UNAM, Mexico D.F.

Meli R (1974) Behaviour of masonry walls under lateral loads. In: Proceedings of the 5th World Conference on Earthquake Engineering, Rome, vol. 1, pp 853-862 
Moroni MO, Astroza M, Mesias P (1996) Displacement capacity and required story drift in confined masonry buildings. In: Proceedings of the 11th World Conference of Earthquake Engineering, Acapulco, paper 1059

Moroni MO, Gomez C, Astroza M (2002) Confined block masonry building. World Housing Encyclopedia, EERI-IAEE, Housing Report \# 7. http://www.world-housing.net/ whereport1view.php?id=100035. Accessed 31 January 2013

NTC (2008) Norme tecniche per le costruzioni (Technical standards for buildings), Ministerial Decree dated of 14-01-2008. Ministero delle Infrastrutture e dei Trasporti, Rome (in Italian)

Ranjbaran F, Hosseini M, Soltani M (2012) Simplified formulation for modeling the nonlinear behavior of confined masonry walls in seismic analysis. International Journal of Architectural Heritage 6(3):259-289. doi:10.1080/15583058.2010.528826

RDCT (2013) R: A language and environment for statistical computing. R Foundation for Statistical Computing, Vienna, Austria. ISBN 3-900051-07-0. http://www.Rproject.org. Accessed 31 January 2013

Riahi Z, Elwood K, Alcocer S (2009) Backbone model for confined masonry walls for performance-based seismic design. J Struct Eng-ASCE 135(6):644-654. doi:10.1061/(ASCE)ST.1943-541X.0000012

San Bartolomé A (1994) Construcciones de albañilería: comportamiento sísmico y diseño estructural (Masonry buildings: seismic behavior and structural design). Fondo Editorial, Pontificia Universidad Católica del Perú, Lima

San Bartolomé A (2007) Defects with incidence in the behavior of the masonry constructions in the Pisco earthquake of 15-08-2007. Blog de Investigaciones en Albañilería. http://blog.pucp.edu.pe/albanileria (in Spanish). Accessed 31 January 2013

Sánchez TA, Alcocer SM, Flores L (1996) Experimental study on a tridimensional confined masonry structure, full-scale and subjected to lateral loads. In: Proceedings of the 10th Mexican Conference of Structural Engineering, Mérida-Yucatán, vol. 2, pp 909-918 (in Spanish)

Shahzada K, Khan A, Elnashai AS, Naseer A, Javed M, Ashraf M (2011) Shake table test of confined brick masonry building. Advanced Materials Research 255-260:689-693. doi:10.4028/www.scientific.net/AMR.255-260.689

Tomaževič M, Klemenc I (1997) Seismic behaviour of confined masonry walls. Earthquake Eng Struc 26(10):1059-1071. doi:10.1002/(SICI)1096-9845(199710)26:10<1059::AIDEQE694>3.0.CO;2-M 
Tomaževič M (1999) Earthquake-resistant design of masonry buildings. Series on Innovation in Structures and Construction, vol. 1. Imperial College Press, London

Tomaževič M (2007) Damage as a measure for earthquake-resistant design of masonry structures: Slovenian experience. Can J Civil Eng 34(11):1403-1412. doi:10.1139/L07128

Turnšek V, Čačovič F (1970) Some experimental results on the strength of brick masonry walls. In: Proceedings of the 2nd International Brick Masonry Conference, Stoke-onTrent, pp 149-156

Witten IH, Frank E (2005) Data mining: Practical machine learning tools and techniques, 2nd edn. Morgan Kaufmann, San Francisco

Zavala C, Honma C, Gibu P, Gallardo J, Huaco, G (2004) Full scale on line test on two story masonry building using handmade bricks. In: Proceedings of the 13th World Conference on Earthquake Engineering, Vancouver, paper 2885

Zepeda J, Alcocer SM, Flores L (2000) Earthquake-resistant construction with multiperforated clay brick walls. In: Proceedings of the 12th World Conference on Earthquake Engineering, Auckland, paper 1541 